\title{
Article \\ Nickelocene-Filled Purely Metallic Single-Walled Carbon Nanotubes: Sorting and Tuning the Electronic Properties
}

\author{
Marianna V. Kharlamova ${ }^{1,2}$ (D) \\ 1 Institute of Materials Chemistry, Vienna University of Technology, Getreidemarkt 9/BC/2, \\ 1060 Vienna, Austria; mv.kharlamova@gmail.com \\ 2 Moscow Institute of Physics and Technology, Institutskii Pereulok 9, 141700 Dolgoprudny, Russia
}

Citation: Kharlamova, M.V.

Nickelocene-Filled Purely Metallic Single-Walled Carbon Nanotubes: Sorting and Tuning the Electronic Properties. Nanomaterials 2021, 11, 2500. https://doi.org/10.3390/ nano11102500

Academic Editors: Philippe Miele and Riccardo Rurali

Received: 23 July 2021

Accepted: 22 September 2021

Published: 26 September 2021

Publisher's Note: MDPI stays neutral with regard to jurisdictional claims in published maps and institutional affiliations.

Copyright: (C) 2021 by the author. Licensee MDPI, Basel, Switzerland. This article is an open access article distributed under the terms and conditions of the Creative Commons Attribution (CC BY) license (https:// creativecommons.org/licenses/by/ $4.0 /)$.

\begin{abstract}
We conducted the filling of single-walled carbon nanotubes (SWCNTs) with nickelocene molecules and separation of the filled SWCNTs by conductivity type by density-gradient ultracentrifugation. We tailored the electronic properties of nickelocene-filled purely metallic SWCNTs by thermal treatment in high vacuum. Our results demonstrated that annealing at low temperatures $\left(360-600{ }^{\circ} \mathrm{C}\right)$ leads to n-doping of SWCNTs, whereas annealing at high temperatures $\left(680-1200{ }^{\circ} \mathrm{C}\right)$ results in p-doping of SWCNTs. We found a correlation between the chemical state of the incorporated substances at different annealing temperatures and its influence on the electronic properties of SWCNTs.
\end{abstract}

Keywords: single-walled carbon nanotube; nickelocene; electronic properties; X-ray photoelectron spectroscopy; Raman spectroscopy

\section{Introduction}

Carbon nanotubes, one-dimensional allotropic modifications of carbon with $\mathrm{sp}^{2}$ hybridization of atoms, can be envisaged as graphene sheets rolled into cylinders. Depending on the number of graphene layers, the nanotubes are classified as single- (SWCNT), double- (DWCNT) and multi-walled. SWCNTs are attracting the attention of researchers thanks to their unique physical and chemical properties, which can be applied in different fields. SWCNTs are promising materials for the next generation of nanoelectronic devices [1]. The properties of SWCNTs are defined by their atomic structure. Contemporary synthesis methods allow preparing the mixture of nanotubes with different structures and properties, limiting their application [2].

To obtain SWCNTs with defined electronic properties, two approaches were developed. The first approach is the separation of synthesized SWCNTs by conductivity type and chiral vector $[3,4]$. The second approach is the modification of the properties of SWCNTs via covalent and noncovalent functionalization of the outer surface of SWCNTs, substitution of atoms in the SWCNT walls by other atoms, intercalation of the bundles of SWCNTs and the filling of the internal channels of SWCNTs [5]. The filling of SWCNTs is a promising method of controllable modification of their electronic properties because substances with different physical and chemical properties can be incorporated inside SWCNTs [6]. In the literature, there are examples of the filling of SWCNTs with electron donors-metals, which lead to raising the Fermi level of SWCNTs $[7,8]$ - and electron acceptors-metal halogenides, which result in lowering the Fermi level of SWCNTs [9-11]. The filling of SWCNTs separated by conductivity type to metallic and semiconducting fractions offers an opportunity to precisely tailor their electronic structure. In the literature, there are only a few examples of filling of metallic and semiconducting SWCNTs by chlorides of silver [12,13] and copper [14].

The filled metallic and semiconducting SWCNTs can be obtained not only by the filling of SWCNTs separated by conductivity type but also by the separation of the filled SWCNTs. Recently, the authors of [15] performed the separation of nickelocene-filled 
SWCNTs to metallic and semiconducting fractions by density gradient ultracentrifugation. This approach has advantages, because it allows not only separating the filled SWCNTs but also cleaning them from non-encapsulated substances.

Metallocene-filled SWCNTs are of special interest because it has been shown that the thermal treatment in a vacuum of filled SWCNTs leads to the formation of inner nanotubes [16]. Annealing of filled SWCNTs results in the decomposition of metallocene with the formation of metal carbide or metal, which act as catalysts for the growth of inner nanotubes [16]. The chemical transformation of metallocene and the growth of inner tubes can lead to the modification of the electronic properties of SWCNTs. This gives an opportunity to tailor the electronic structure of metallocene-filled SWCNTs by annealing at different temperatures. At the same time, there are no reports in the literature on studies of the thermal treatment-induced modification of the electronic properties of metallocene-filled metallic SWCNTs separated by the conductivity-type.

In this study, we close this gap by investigating the electronic properties of nickelocenefilled high-purity metallic SWCNTs annealed at temperatures between 360 and $1200{ }^{\circ} \mathrm{C}$ by $\mathrm{X}$-ray photoelectron spectroscopy (XPS). The chemical state of the filler at different annealing temperatures is studied by XPS. The growth process of inner tubes is investigated by Raman spectroscopy. On the basis of the obtained data, we found a correlation between the chemical state of the incorporated substances and its influence on the electronic properties of SWCNTs.

\section{Materials and Methods}

SWCNTs with mixed-conductivity type and a mean diameter of $1.67 \mathrm{~nm}$ were used for filling with nickelocene. The SWCNTs were synthesized by the chemical vapor deposition method [17]. Prior to filling, the ends of the SWCNTs were opened by annealing in air at $500{ }^{\circ} \mathrm{C}$ for $1 \mathrm{~h}$. Then, the SWCNTs and an excess of nickelocene powder $\left(\mathrm{NiCp}_{2}\right.$, chemical formula $\left(\mathrm{C}_{5} \mathrm{H}_{5}\right)_{2} \mathrm{Ni}, 99 \%$, Strem Chemicals Inc., Bischheim, France) were put into Pyrexglass ampoules. The ampoules were evacuated at a pressure of $10^{-6} \mathrm{mbar}$ for $20 \mathrm{~min}$ and sealed. Half of the ampoule was heated up to a temperature of $50{ }^{\circ} \mathrm{C}$; this led to the evaporation of nickelocene and its condensation in the colder half of the ampoule. Depending on the amount of nickelocene, this process took between 12 and $24 \mathrm{~h}$. After that, the position of the ampoule was flipped so that the nickelocene containing half of the ampoule was heated. This procedure was repeated 5-10 times over 5 days. Then, the filled SWCNTs were separated into metallic and semiconducting fractions by density-gradient ultracentrifugation. The details of the separation procedure are described in Reference [15]. The filled metallic SWCNTs were annealed in a high vacuum $\left(10^{-6} \mathrm{mbar}\right)$ at temperatures between 360 and $1200{ }^{\circ} \mathrm{C}$ for $2 \mathrm{~h}$.

The investigation of the samples by XPS was performed with a VG Scienta XPS spectrometer using monochromatic $\mathrm{Al} \mathrm{K}$ _ radiation with an energy of $1486.6 \mathrm{eV}$ and semispherical photoelectron analyzer SCIENTA RS4000. The samples, in the form of buckypapers with a size of $5 \times 5 \mathrm{~mm}$, were mounted on Mo holders. The measurements were conducted at room temperature. The calibration of the energy scale was performed using the position of the $A u 4 f_{7 / 2}$ peak at $83.96 \mathrm{eV}$. The investigation of the samples by Raman spectroscopy was conducted with a Horiba Jobin Yvon LabRAM HR800 spectrometer using a laser wavelength of $514 \mathrm{~nm}$ (ArKr, Coherent Innova 70c, Dieburg, Germany). The measurements were performed directly on the SWCNT buckypapers at room temperature. The fitting of the obtained spectra with Voigtian functions was performed with PeakFit 4.12. The accuracy in the peak positions is $\pm 2 \mathrm{~cm}^{-1}$.

\section{Results}

Figure 1a shows the C 1s XPS spectra of nickelocene-filled SWCNTs and samples annealed at temperatures between 360 and $1200{ }^{\circ} \mathrm{C}$ for $2 \mathrm{~h}$. The spectra of all samples include a single peak, which is positioned at a binding energy of $284.73 \mathrm{eV}$ for nickelocenefilled SWCNTs. The annealing of the filled SWCNTs leads to the shift of the peak. Figure $1 \mathrm{~b}$ 
presents the dependence of the peak position and its shift relative to the position of the unannealed sample on the annealing temperature. The annealing at a temperature of $360{ }^{\circ} \mathrm{C}$ leads to the shift of the peak by $0.11 \mathrm{eV}$ towards higher binding energies. As annealing temperatures increase, the peak shifts gradually towards lower binding energies and almost reaches the position of the unannealed sample at $600{ }^{\circ} \mathrm{C}$. The annealing at a temperature of $800{ }^{\circ} \mathrm{C}$ leads to the further shift of the peak by $0.04 \mathrm{eV}$. As annealing temperatures increase, the peak position changes insignificantly, and the maximal shift of the peak of $0.06 \mathrm{eV}$ is observed at a temperature of $1200^{\circ} \mathrm{C}$. The observed shift of the peak towards higher binding energies during annealing at low temperatures $\left(360-600^{\circ} \mathrm{C}\right)$ and towards lower binding energies during annealing at high temperatures $\left(680-1200{ }^{\circ} \mathrm{C}\right)$ is caused by the modification of the electronic properties of SWCNTs.

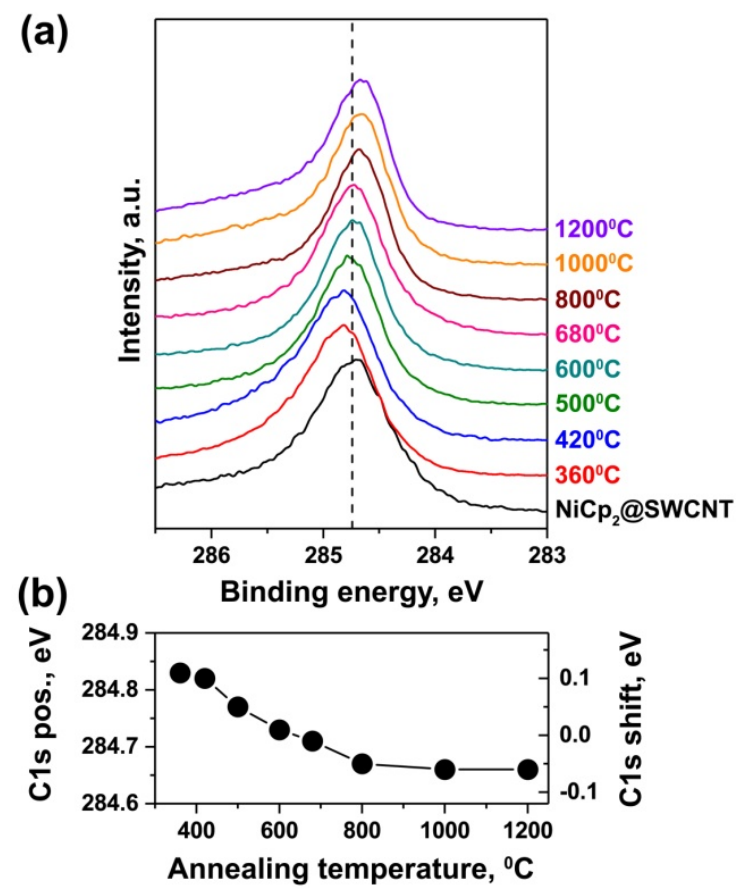

Figure 1. (a) The C1s XPS spectra of nickelocene-filled SWCNTsand samples annealed at temperatures between 360 and $1200{ }^{\circ} \mathrm{C}$ for $2 \mathrm{~h}$. (b) The dependence of the position of the C1s peak and its shift relative to the position for unannealed sampleson annealing temperatures.

According to the literature data, the shift of the C1s XPS peak towards higher binding energies was observed for SWCNTs intercalated by alkali metals [18] and filled with ferrocene [19] and europium [20]. The appearance of additional components at higher binding energies as compared to the peak of the pristine SWCNTs was observed in the C 1s XPS spectra of SWCNTs filled with silver and copper $[7,8]$. This was explained by the charge transfer from encapsulated substances to the SWCNTs, i.e., n-doping of SWCNTs. The shift of the C1s XPS peak toward lower binding energies was observed for SWCNTs filled with metallofullerene Gd@C82 [21], cerocene molecules [22] and erbium chloride [23]. The appearance of additional components at lower binding energies as compared to the peak of the pristine SWCNTs was observed in the C1s XPS spectra of SWCNTs filled with metal halogenides [9-11]. This was explained by the charge transfer from the SWCNTs to encapsulated substances, i.e., p-doping of SWCNTs. Taking into consideration this interpretation of the shifts of the peaks in the C1s XPS spectra, we can conclude that the annealing of nickelocene-filled SWCNTs at low temperatures $\left(360-600{ }^{\circ} \mathrm{C}\right)$ leads to n-doping of SWCNTs, whereas the annealing at high temperatures $\left(680-1200^{\circ} \mathrm{C}\right)$ results in p-doping of SWCNTs.

In order to explain the modification of the electronic properties of SWCNTs observed with the thermal treatment of nickelocene-filled SWCNTs, we investigated the chemical 
state of the filler at different annealing temperatures. Figure 2 shows the Ni 2p XPS spectra of SWCNTs filled with nickelocene and samples annealed at temperatures of $360-1200{ }^{\circ} \mathrm{C}$ for $2 \mathrm{~h}$. The spectrum of nickelocene-filled SWCNTs includes two broad peaks positioned at binding energies of 854.7 and $872.2 \mathrm{eV}$; they belong to $\mathrm{Ni} 2 \mathrm{p}_{3 / 2}$ and $\mathrm{Ni} 2 \mathrm{p}_{1 / 2}$ core levels. The peak positions are close to the ones of pure nickelocene [24]. These peaks have an asymmetric shape because of the presence of shoulders at binding energies of 856.1 and $873.7 \mathrm{eV}$. They belong to oxidized nickel, which was formed during the treatment of nickelocene-filled SWCNTs with chemicals in the process of separation.

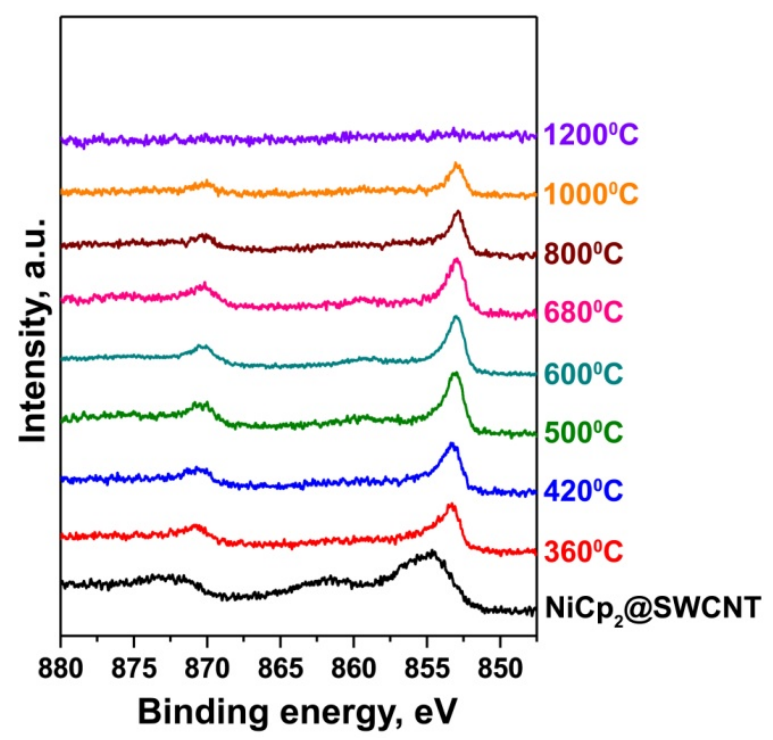

Figure 2. The Ni 2p XPS spectra of nickelocene-filled SWCNTs and samples annealed at temperatures between 360 and $1200{ }^{\circ} \mathrm{C}$ for $2 \mathrm{~h}$.

During annealing at a temperature of $360{ }^{\circ} \mathrm{C}$, the $\mathrm{Ni} 2 \mathrm{p}_{3 / 2}$ and $\mathrm{Ni} 2 \mathrm{p}_{1 / 2}$ peaks shift by $1.4 \mathrm{eV}$ toward lower binding energies. This is explained by the change in the chemical state of nickel as a result of the decomposition of nickelocene with the formation of nickel carbide. It is not clear whether the carbon atoms needed to form the carbide arose from the SWCNTs (perhaps from the inner tubes) or from the ligands of the nickelocene molecules.With increasing annealing temperatures, the $\mathrm{Ni} 2 \mathrm{p}_{3 / 2}$ and $\mathrm{Ni} 2 \mathrm{p}_{1 / 2}$ peaks are narrowed and further shift towards lower binding energies, reaching the position of metallic nickel (for which the $\mathrm{Ni} 2 \mathrm{p}_{3 / 2}$ peak is positioned at a binding energy of $\sim 853 \mathrm{eV}$ [25]) at $600{ }^{\circ} \mathrm{C}$. This data proves that metastable nickel carbides transform to stable metallic nickel. This conclusion is in agreement with the reported results that showed that nickel carbides (in particular, $\mathrm{Ni3C}$ ) are metastable and decompose at temperatures higher than $400-500{ }^{\circ} \mathrm{C}[26,27]$. With annealing temperatures increasing higher than $600{ }^{\circ} \mathrm{C}$, the intensity of the $\mathrm{Ni} 2 \mathrm{p} 3 / 2$ and $\mathrm{Ni} 2 \mathrm{p}_{1 / 2}$ peaks gradually decreases; this corresponds to releasing nickel from the nanotube channels until its complete removal during annealing at the maximal temperature of $1200^{\circ} \mathrm{C}$. A similar trend was observed during the annealing of ferrocene-filled SWCNTs [16].

Regarding the Ni concentration, there is a high nickel content in the nickelocene-filled SWCNTs. The atomic ratio of nickel-to-carbon amounts to 0.0141 . The annealing of the filled SWCNTs leads to the removal of nickel from the sample. At $500{ }^{\circ} \mathrm{C}$, the atomic ratio of nickel-to-carbon amounts to 0.0100 , which corresponds to a nickel content of $71 \%$. At $800{ }^{\circ} \mathrm{C}$, the atomic ratio of nickel-to-carbon amounts to 0.0047 , which corresponds to a nickel content of $33 \%$. Finally, at $1200{ }^{\circ} \mathrm{C}$, the atomic ratio of nickel-to-carbon amounts to 0.0004 , which corresponds to a nickel content of $3 \%$.

Not only the thermal treatment-induced chemical transformation of nickelocene but also the growth process of inner nanotubes influences the electronic properties of the host SWCNTs. To investigate the growth process of inner tubes, the samples were studied by 
Raman spectroscopy. Figure 3a shows the radial breathing mode (RBM) bands of Raman spectra of the pristine SWCNTs, nickelocene-filled SWCNTs and samples annealed at temperatures of $400-1000{ }^{\circ} \mathrm{C}$ for $2 \mathrm{~h}$. The RBM-band of the pristine SWCNTs includes an intense peak at $145 \mathrm{~cm}^{-1}$, which corresponds to the nanotubes with a diameter of $1.7 \mathrm{~nm}$ [28]. The RBM-band of nickelocene-filled SWCNTs includes the peak shifted by $19 \mathrm{~cm}^{-1}$ towards lower frequencies, which is common for molecule-filled SWCNTs [16]. The spectra of the annealed samples show the appearance of additional peaks of inner tubes. These peaks are positioned at frequencies of 198, 207, 242, 255 and $263 \mathrm{~cm}^{-1}$ and, according to the Kataura plot [29], correspond to the nanotubes with chiralities of $(13,3),(14,1),(7,7)$, $(8,5)$ and $(9,3)$ and diameters of 1.16, 1.14, $0.95,0.90$ and $0.85 \mathrm{~nm}$, respectively. Taking into consideration the mean diameter of the pristine SWCNTs $(1.67 \mathrm{~nm})$ and doubled van der Waals distance between graphene layers of DWCNTs $(0.67 \mathrm{~nm})$, we conclude that the mean diameter of inner nanotubes amounts to $1.0 \mathrm{~nm}$. Figure $3 \mathrm{~b}$ shows the dependence of normalized area intensity of the peak of the $(7,7)$ tube with the mean diameter on the annealing temperature. It is visible that the intensity of the peak of this tube increases at temperatures between 450 and $550{ }^{\circ} \mathrm{C}$ and stays unchanged at higher annealing temperatures. Consequently, the sample consists of SWCNTs and DWCNTs at temperatures of $450-550{ }^{\circ} \mathrm{C}$, and it contains filled or empty DWCNTs at temperatures higher than $550^{\circ} \mathrm{C}$.

\section{(a)}

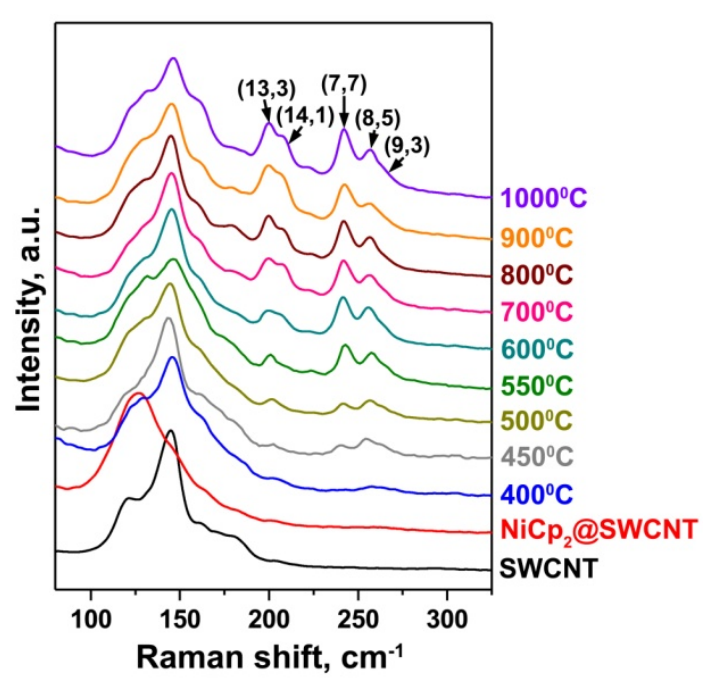

(b)

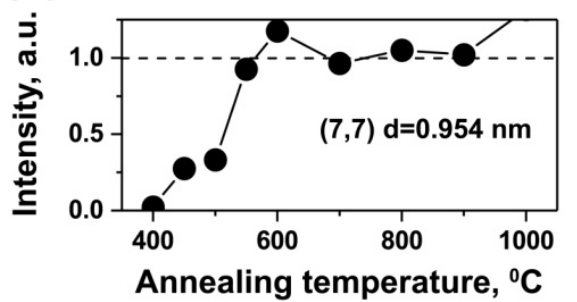

Figure 3. (a) The RBM-band of Raman spectra of SWCNTs, nickelocene-filled SWCNTs and samples annealed at temperatures between 400 and $1000^{\circ} \mathrm{C}$ for $2 \mathrm{~h}$. The chiral vectors of inner nanotubes are denoted. (b) The dependence of normalized intensity of the peak of inner tube with chirality of $(7,7)$ on annealing temperature.

Thus, there are three overlapping temperature-dependent processes that influence the electronic properties of SWCNTs: (i) chemical transformation of nickelocene, (ii) inner tube growth and (iii) removal of nickel from the nanotubes. These materials might be expected to behave in a manner that is consistent with prior theoretical and experimental studies of analogous materials [19]. During annealing at low temperatures, nickelocene transformed to nickel carbides and metallic nickel, which led to n-doping of SWCNTs. During annealing at higher temperatures, inner tube growth and removal of filler from 
the nanotubes occurred, which led to the formation of empty DWCNTs. In the DWCNTs, p-doping of the outer tubes by inner tubes was present, which is in agreement with the data of theoretical modeling [30]. Figure 4 shows the schematics of the band structures of the pristine metallic SWCNTs and the Fermi level shifts in nickelocene-filled SWCNTs annealed at temperatures between 360 and $1200{ }^{\circ} \mathrm{C}$.
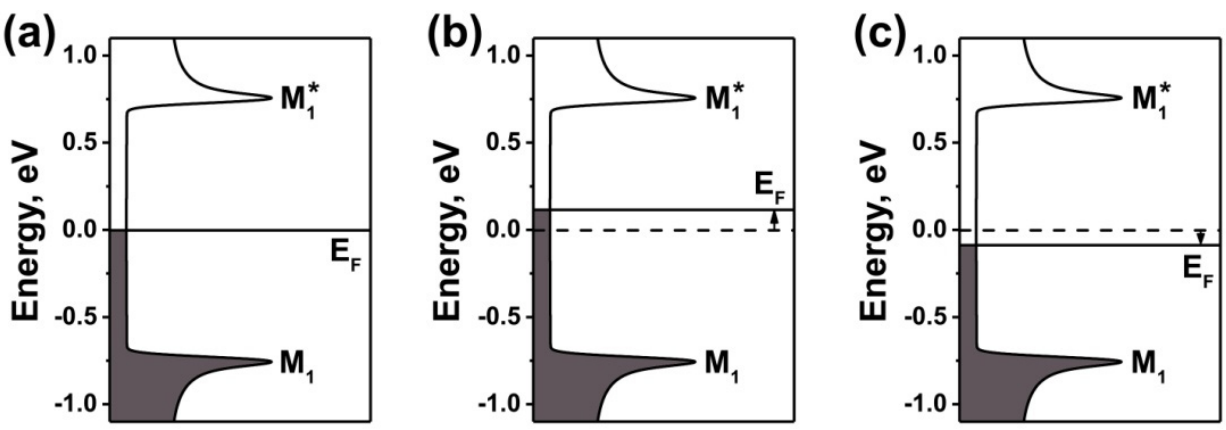

Figure 4. The schematics of the band structures of metallic SWCNTs (a) and nickelocene-filled SWCNTs annealed at temperatures of $360-600{ }^{\circ} \mathrm{C}(\mathbf{b})$ and $680-1200{ }^{\circ} \mathrm{C}$ (c) for $2 \mathrm{~h}$. $\mathrm{E}_{\mathrm{F}}$ is the Fermi level, and $\mathrm{M} 1$ and $\mathrm{M} 1^{*}$ are the first $\mathrm{vHs}$ in the valence and conduction band, respectively. The Fermi level shift is indicated by arrows.

\section{Conclusions}

In conclusion, we tailored the electronic properties of nickelocene-filled purely metallic SWCNTs by thermal treatment in a high vacuum. It was shown that annealing at low temperatures $\left(360-600^{\circ} \mathrm{C}\right)$ led to n-doping of SWCNTs, whereas annealing at high temperatures $\left(680-1200^{\circ} \mathrm{C}\right)$ resulted in p-doping of SWCNTs.

Funding: M.V.K. acknowledges funding for postdocs with experience of international work inleading research centers for conducting research in leading laboratories of the Moscow Institute of Physics and Technology.

Institutional Review Board Statement: Not applicable.

Informed Consent Statement: Not applicable.

Data Availability Statement: Not applicable.

Acknowledgments: I thank Christian Kramberger for assistance in density gradient centrifugation and Raman spectroscopy investigation of the samples, Markus Sauer for assistance in XPS measurements of the samples, Kazuhiro Yanagi for assistance in density gradient centrifugation of the samples.

Conflicts of Interest: The author declare no conflict of interest. The funders had no role in the design of the study; in the collection, analyses, or interpretation of data; in the writing of the manuscript; or in the decision to publish the results.

\section{References}

1. Endo, M.; Strano, M.S.; Ajayan, P.M. Potential applications of carbon nanotubes. In Carbon Nanotubes: Topics in Applied Physics; Springer: Berlin, Germany, 2008; pp. 13-61.

2. Joselevich, E.; Dai, H.J.; Liu, J.; Hata, K.; Windle, A.H. Carbon nanotube synthesis and organization. In Carbon Nanotubes: Topics in Applied Physics; Springer: Berlin, Germany, 2008; pp. 101-164.

3. Green, A.A.; Hersam, M.C. Nearly Single-Chirality Single-Walled Carbon Nanotubes Produced via Orthogonal Iterative Density Gradient Ultracentrifugation. Adv. Mater. 2011, 23, 2185-2190. [CrossRef]

4. Liu, H.P.; Nishide, D.; Tanaka, T.; Kataura, H. Large-scale single-chirality separation of single-wall carbon nanotubes by simple gel chromatography. Nat. Commun. 2011, 2, 309. [CrossRef] [PubMed]

5. Kharlamova, M.V. Electronic properties of pristine and modified single-walled carbon nanotubes. Phys. Uspekhi 2013, 56, 1047-1073. [CrossRef]

6. Kharlamova, M.V. Advances in tailoring the electronic properties of single-walled carbon nanotubes. Prog. Mater. Sci. 2016, 77, 125-211. [CrossRef] 
7. Kharlamova, M.V.; Niu, J.J. Donor doping of single-walled carbon nanotubes by filling of channels with silver. J. Exp. Theor. Phys. 2012, 115, 485-491. [CrossRef]

8. Kharlamova, M.V.; Niu, J.J. New method of the directional modification of the electronic structure of single-walled carbon nanotubes by filling channels with metallic copper from a liquid phase. JETP Lett. 2012, 95, 314-319. [CrossRef]

9. Kharlamova, M.V.; Eliseev, A.A.; Yashina, L.V.; Petukhov, D.I.; Liu, C.P.; Wang, C.Y.; Semenenko, D.A.; Belogorokhov, A.I. Study of the electronic structure of single-walled carbon nanotubes filled with cobalt bromide. JETP Lett. 2010, 91, 196-200. [CrossRef]

10. Kharlamova, M.V.; Yashina, L.V.; Volykhov, A.A.; Niu, J.J.; Neudachina, V.S.; Brzhezinskaya, M.M.; Zyubina, T.S.; Belogorokhov, A.I.; Eliseev, A.A. Acceptor doping of single-walled carbon nanotubes by encapsulation of zinc halogenides. Eur. Phy. J. B 2012, 85, 34. [CrossRef]

11. Kharlamova, M.V.; Yashina, L.V.; Eliseev, A.A.; Volykhov, A.A.; Neudachina, V.S.; Brzhezinskaya, M.M.; Zyubina, T.S.; Lukashin, A.V.; Tretyakov, Y.D. Single-walled carbon nanotubes filled with nickel halogenides: Atomic structure and doping effect. Phys. Status Solidi B 2012, 249, 2328-2332. [CrossRef]

12. Kharlamova, M.V.; Kramberger, C.; Mittelberger, A.; Yanagi, K.; Pichler, T.; Eder, D. Silver chloride encapsulation-induced modifications of Raman modes of metallicity sorted semiconducting single-walled carbon nanotubes. J. Spectrosc. 2018, 2018, 5987428. [CrossRef]

13. Kharlamova, M.V.; Kramberger, C.; Domanov, O.; Mittelberger, A.; Yanagi, K.; Pichler, T.; Eder, D. Fermi level engineering of metallicity-sorted metallic single-walled carbon nanotubes by encapsulation of few-atom-thick crystals of silver chloride. J. Mater Sci. 2018, 53, 13018-13029. [CrossRef]

14. Fedotov, P.V.; Eremina, V.A.; Tonkikh, A.A.; Chernov, A.I.; Obraztsova, E.D. Enhanced optical transparency of films formed from sorted metallic or semiconducting single-walled carbon nanotubes filled with CuCl. Phys. Status Solidi B 2016, 253, 2400-2405. [CrossRef]

15. Kharlamova, M.V.; Kramberger, C.; Yanagi, K.; Sauer, M.; Saito, T.; Pichler, T. Separation of Nickelocene-Filled Single-Walled Carbon Nanotubes by Conductivity Type and Diameter. Phys. Status Solidi B 2017, 254, 1700178. [CrossRef]

16. Shiozawa, H.; Pichler, T.; Gruneis, A.; Pfeiffer, R.; Kuzmany, H.; Liu, Z.; Suenaga, K.; Kataura, H. A Catalytic Reaction Inside a Single-Walled Carbon Nanotube. Adv. Mater. 2008, 20, 1443-1449. [CrossRef]

17. Saito, T.; Ohshima, S.; Okazaki, T.; Ohmori, S.; Yumura, M.; Iijima, S. Selective Diameter Control of Single-Walled Carbon Nanotubes in the Gas-Phase Synthesis. J. Nanosci. Nanotechnol. 2008, 8, 6153-6157. [CrossRef] [PubMed]

18. Kramberger, C.; Rauf, H.; Knupfer, M.; Shiozawa, H.; Batchelor, D.; Rubio, A.; Kataura, H.; Pichler, T. Potassium-intercalated single-wall carbon nanotube bundles: Archetypes for semiconductor/metal hybrid systems. Phys. Rev. B 2009, 79, 195442 [CrossRef]

19. Shiozawa, H.; Pichler, T.; Kramberger, C.; Gruneis, A.; Knupfer, M.; Buchner, B.; Zolyomi, V.; Koltai, J.; Kurti, J.; Batchelor, D.; et al. Fine tuning the charge transfer in carbon nanotubes via the interconversion of encapsulated molecules. Phys. Rev. B 2008, 77, 153402. [CrossRef]

20. Nakanishi, R.; Kitaura, R.; Ayala, P.; Shiozawa, H.; de Blauwe, K.; Hoffmann, P.; Choi, D.; Miyata, Y.; Pichler, T.; Shinohara, H. Electronic structure of Eu atomic wires encapsulated inside single-wall carbon nanotubes. Phys. Rev. B 2012, 86, 115445. [CrossRef]

21. Ayala, P.; Kitaura, R.; Kramberger, C.; Shiozawa, H.; Imazu, N.; Kobayashi, K.; Mowbray, D.J.; Hoffmann, P.; Shinohara, H.; Pichler, T. A Resonant Photoemission Insight to the Electronic Structure of Gd Nanowires Templated in the Hollow Core of SWCNTs. Mater. Express 2011, 1, 30-35. [CrossRef]

22. Shiozawa, H.; Kramberger, C.; Rummeli, M.; Batchelor, D.; Kataura, H.; Pichler, T.; Silva, S.R.P. Electronic properties of singlewalled carbon nanotubes encapsulating a cerium organometallic compound. Phys. Status Solidi B 2009, 246, 2626-2630. [CrossRef]

23. Ayala, P.; Kitaura, R.; Nakanishi, R.; Shiozawa, H.; Ogawa, D.; Hoffmann, P.; Shinohara, H.; Pichler, T. Templating rare-earth hybridization via ultrahigh vacuum annealing of $\mathrm{ErCl}_{3}$ nanowires inside carbon nanotubes. Phys. Rev. B 2011, 83, 085407. [CrossRef]

24. Pugmire, D.L.; Woodbridge, C.M.; Langell, M.A. Orientation of nickelocene on Ag(100). Surf. Sci. 1998, 411, L844-L848. [CrossRef]

25. Kim, K.S.; Winograd, N. X-ray photoelectron spectroscopic studies of nickel-oxygen surfaces using oxygen and argon ionbombardment. Surf. Sci. 1974, 43, 625-643. [CrossRef]

26. Leng, Y.G.; Shao, H.Y.; Wang, Y.T.; Suzuki, M.; Li, X.G. A New Method to Synthesize Nickel Carbide (Ni ${ }_{3}$ C) Nanoparticles in Solution. J. Nanosci. Nanotechnol. 2006, 6, 221-226. [CrossRef] [PubMed]

27. Kovacs, G.J.; Bertoti, I.; Radnoczi, G. X-ray photoelectron spectroscopic study of magnetron sputtered carbon-nickel composite films. Thin Solid Films 2008, 516, 7942-7946. [CrossRef]

28. Araujo, P.T.; Maciel, I.O.; Pesce, P.B.C.; Pimenta, M.A.; Doorn, S.K.; Qian, H.; Hartschuh, A.; Steiner, M.; Grigorian, L.; Hata, K.; et al. Nature of the constant factor in the relation between radial breathing mode frequency and tube diameter for single-wall carbon nanotubes. Phys. Rev. B 2008, 77, 241403. [CrossRef]

29. Kataura, H.; Kumazawa, Y.; Maniwa, Y.; Umezu, I.; Suzuki, S.; Ohtsuka, Y.; Achiba, Y. Optical properties of single-wall carbon nanotubes. Synth. Met. 1999, 103, 2555-2558. [CrossRef]

30. Zolyomi, V.; Koltai, J.; Rusznyak, A.; Kuerti, J.; Gali, A.; Simon, F.; Kuzmany, H.; Szabados, A.; Surjan, P.R. Intershell interaction in double walled carbon nanotubes: Charge transfer and orbital mixing. Phys. Rev. B 2008, 77, 245403. [CrossRef] 